\title{
Effect of humidity on electrical conductivity of zinc stearate nanofilms
}

\author{
Serdar Ozturk $^{\mathrm{a}}$, Devrim Balkose ${ }^{\mathrm{a}}$, Salih Okur ${ }^{\mathrm{b}, *}$, Junzo Umemura $^{\mathrm{c}}$ \\ ${ }^{a}$ Department of Chemical Engineering, Izmir Institute of Technology, Gulbahce Campus, Urla, Izmir 35430, Turkey \\ ${ }^{\mathrm{b}}$ Department of Physics, Faculty of Science, Izmir Institute of Technology, Gulbahce Campus, Urla, Izmir 35430, Turkey \\ ${ }^{\mathrm{c}}$ Changchun Institute of Applied Chemistry, Chinese Academy of Sciences, 5625 Renmin Street, Changchun, Jilin 130022, China \\ Received 15 October 2006; received in revised form 22 January 2007; accepted 26 January 2007 \\ Available online 3 February 2007
}

\begin{abstract}
In this work, stearic acid (StAc) and zinc stearate ( $\left.\mathrm{ZnSt}_{2}\right)$ nanofilms were deposited on glass and silver substrates using Langmuir-Blodgett (LB) film technique and their structural and electrical properties were investigated. X-ray diffraction and IR techniques revealed that more crystalline and better films were obtained from $\mathrm{ZnSt}_{2}$ compare to StAc. Electrical conductivity of $\mathrm{ZnSt}_{2} \mathrm{LB}$ films with 13 layers having $28 \mathrm{~nm}$ thickness were measured in the range of humidity of $20-60 \%$ and it is seen that the conductivity was very sensitive to relative humidity (RH) above $40 \%$ at $25{ }^{\circ} \mathrm{C}$ and showed no hysteresis during adsorption and desorption of water vapor. Water vapor adsorption isotherm of $\mathrm{ZnSt}_{2}$ powders was determined and conductivity increase with humidity was attributed to water vapor adsorption.

Constant electrical conductivity of the $\mathrm{ZnSt}_{2}$ films at low relative humidities and at low voltage values is an advantageous property which allows using them as organic nanofilms with insulating properties.
\end{abstract}

(C) 2007 Elsevier B.V. All rights reserved.

Keywords: Zinc stearate; Langmuir-Blodgett films; Electrical conductivity; Humidity effect

\section{Introduction}

Thin organic films, which have a thickness of a few nanometers are used in many practical and commercial applications such as sensors, displays, non-linear optical materials or electroluminescent emitters and electronic circuit components. An organic thin film can be deposited on a solid substrate by various techniques such as thermal evaporation, sputtering, molecular beam epitaxy, adsorption from solution, self-assembly, Langmuir-Blodgett (LB) technique, etc. Among these, LB technique is one of the most promising deposition methods since it offers the precise control of the monolayer thickness and homogeneous deposition of the monolayer over large areas and monolayer can be deposited to almost any kind of solid substrate. It is also possible to make multilayer structures with varying layer composition at desired molecular architecture [1]. Designing and synthesizing novel functional molecular materials for molecular device purposes are a challenging task for researchers. In this point of view, Kusano

\footnotetext{
* Corresponding author. Tel.: +90 232750 7517; fax: +90 2327507509

E-mail address: salihokur@iyte.edu.tr (S. Okur).
}

et al. tried to use cellulose LB films as humidity sensor and Petty showed the effect of humidity on electrical measurements [2-4].

Long chain fatty acid/salts have been extensively studied as LB monolayers and multilayers. Avila et al. reported that the monolayer properties such as film stability and molecular packing arrangement were significantly affected by $\mathrm{pH}$, temperature, addition of ions, and dipping and barrier speeds [5]. Various methods such as FTIR, AFM, XRD, etc. have been used to investigate structural and surface properties, and molecular orientation and conformation of LB films. The inhomogeneities and the defects were detected using these techniques [6,7]. Kumar et al. reported that zinc arachidate LB multilayers have hexagonal layer plane packing with tilted molecules [8].

Electrical investigations of LB films have generally fallen into three main categories, namely conductivity studies, photoelectrical measurements and enhanced semiconductor studies. The electrical conduction of an LB multilayer depends on several factors such as molecular and film structure, degree of intermolecular charge transfer, defect density, the ambient conditions and so on [9]. Exposing of LB films to low levels of gases changes electrical conductivity. Kim et al. measured electrical 


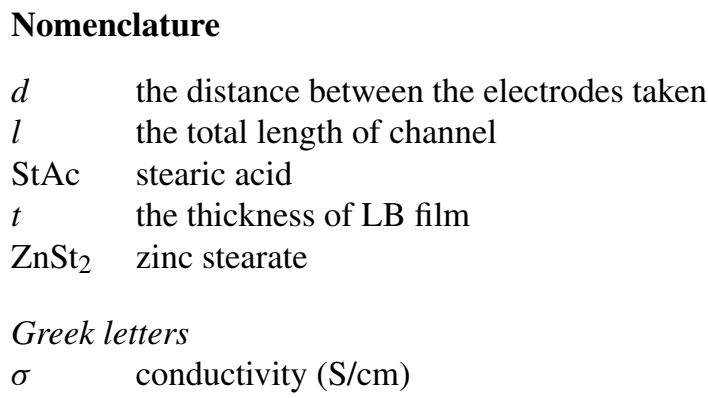

conductivity of stearic acid LB film to be around $10^{-8} \mathrm{~S} / \mathrm{cm}$ in air and they also showed conductivity changes with injection of organic gases [10].

In this paper, LB film technique was used to fabricate $\mathrm{ZnSt}_{2}$ nanofilms. Investigation of composition and structural organization of films on glass and silver coated glass was performed by FTIR, AFM, and XRD methods. For comparison, StAc nanofilms were also fabricated and identified at this stage. Then, electrical measurements of $\mathrm{ZnSt}_{2}$ were achieved in the air at different relative humidities at $25^{\circ} \mathrm{C}$.

\section{Experimental}

\subsection{Materials}

Ultra pure water (with $18.3 \mathrm{M} \Omega \mathrm{cm}$ resistivity) deionized using Elix 5 Millipore Milli-Q-Gradient Millipore system was used to prepare water subphase mixture. The glass substrates were purchased from Marienfeld. Bare and silver coated glass slides were used to investigate electrical characteristics of $\mathrm{ZnSt}_{2}$ LB films. For this purpose, silver was evaporated thermally in vacuum chamber (Leybold Univex 300) with the base pressure $5.0 \times 10^{-6}$ Torr. Stearic acid ( $>99.5 \%$, Fluka, $99 \%$, Nacalai) was used as a monolayer material. Benzene (>99.5\%, Riedel-deHaen) was employed as spreading solvent. They were used as it is without further purification. Zinc chloride ( $>99.9 \%$, Wako, $98-100.5 \%$, Merck) was added to the water subphase for zinc stearate monolayer deposition. $\mathrm{ZnSt}_{2}$ (Baerlocher) in powder form was used for water vapor adsorption measurement.

\subsection{Substrate and equipment preparation}

Glass substrates were cleaned in an ultrasonic bath with the sequence of solvents such as acetone, 2-propanol, ethanol and finally with $\mathrm{NaOH}(1 \mathrm{M})$. Then, the glass substrates were rinsed three times and kept in deionized water.

The glass substrates were coated with a silver layer of $70-80 \mathrm{~nm}$ thickness in the vacuum chamber at around $5 \times 10^{-6}$ Torr base pressure. The thickness of coated silver on glass was around $70-80 \mathrm{~nm}$.

Barriers and teflon trough of the LB film system were rinsed with pure deionized water after cleaning with acetone and ethanol before each experiment.

\subsection{Monolayer formation}

KSV 3000 LB system with automated surface balance was used to form the monolayer and Langmuir-Blodgett films. Aqueous subphase surface cleaning prior to monolayer spreading was done by simply "washing" the subphase surface with benzene. Benzene solution of StAc with the concentration of $0.92 \mathrm{mg} / \mathrm{ml}$ was prepared as stock solution and stored at $4{ }^{\circ} \mathrm{C}$ in the refrigerator. Hundred microliters of the solutions were spread by Hamilton microliter syringe onto the subphase solution by distributing the droplets over the entire trough area at $20 \pm 0.5^{\circ} \mathrm{C}$.

During monolayer formation, temperature, $\mathrm{pH}$, concentration of subphase solution and the amount of monolayer material were changed to reach the optimum conditions. The $\mathrm{pH}$ of subphase solution was adjusted by $\mathrm{NaOH}(1 \mathrm{M})$ and $\mathrm{HCl}(1 \mathrm{M})$ solution.

\subsection{Deposition of LB films}

The spread monolayer solutions were allowed to evaporate in $30 \mathrm{~min}$ before compressing the monolayer to the desired target surface pressure value. Then, the monolayers were compressed with a rate of $3 \mathrm{~mm} / \mathrm{min}$ while the surface pressure was recorded using a Wilhelmy platinum plate with a resolution of $0.004 \mathrm{mN} / \mathrm{m}$. At the target surface pressure, the monolayers were allowed to stabilize for $5 \mathrm{~min}$ before conventional dipping.

Monolayers were deposited by vertical dipping method (Y type) onto either bare or silver coated glass slide at a constant surface pressure in the range of $25 \mathrm{mN} / \mathrm{m}$ for stearic acid and $10 \mathrm{mN} / \mathrm{m}$ for $\mathrm{ZnSt}_{2}$ with $2 \mathrm{~mm} / \mathrm{min}$ dipping speed. Zinc stearate LB films were prepared at $5 \times 10^{-4} \mathrm{M}$ metal salt concentration in the subphase $\mathrm{pH}$ 6.3.

The transfer ratios between 0.7 and 1.0 were obtained throughout the experiments. After the deposition of the first monolayer, LB films were kept dry in a desiccator with $\mathrm{P}_{2} \mathrm{O}_{5}$ for at least $15 \mathrm{~h}$ and then the required number of layers were transferred. Moreover, during multilayer transfer, the substrate with LB film was dried between each cycle for $20 \mathrm{~min}$. The produced multilayer $\mathrm{HSt}$ and of $\mathrm{ZnSt}_{2}$ films were finally stored in a $\mathrm{P}_{2} \mathrm{O}_{5}$ dessicator prior to characterization. $\mathrm{Y}$ type depositions were obtained by this technique.

For conductivity measurements, a glass slide was coated with a silver layer. Thin Ag layer was separated into two parts by a continuous channel made by using a steel needle. The width of this channel was around 60-70 $\mu \mathrm{m}$ as measured by AFM contact mode as seen in Fig. 1. The $13 \mathrm{LB}$ layers of $\mathrm{ZnSt}_{2}$ were deposited onto it by LB technique. Total length of the channel measured with a caliper was around $36 \mathrm{~cm}$.

\subsection{Characterization of LB films}

Intralayer structure of the LB films was determined by using X-ray powder diffractometer (Phillips X'Pert Pro) using Grazing Incidence attachment at $20^{\circ} \mathrm{C}$. $\mathrm{Cu} \mathrm{K} \alpha$ radiation with Ni filter was used under $45 \mathrm{kV}$ and $40 \mathrm{~mA}$. Each scan was performed in the $2-70^{\circ} 2 \theta$ range. Using this technique, lattice structure, d- 
(a)

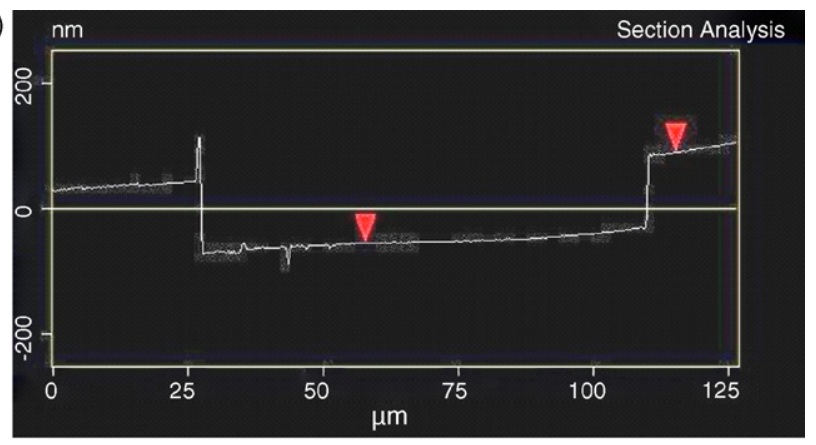

(b)

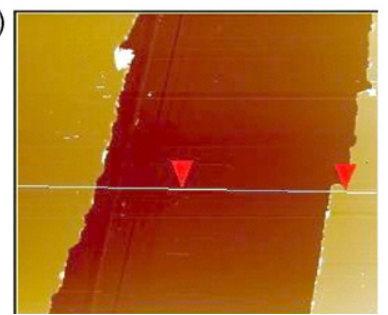

Fig. 1. (a) Section analysis and (b) AFM image of related channel showing the distance between two silver electrodes for in-plane measurements.

spacings and tilting angles were defined with the Bragg's law. Crystal size was calculated according to Scherrer equation from diffraction patterns.

The infrared spectra of LB films were recorded on a specular reflectance accessory with $80^{\circ}$ (Pike Technologies), in the reflection-absorption mode with Excalibur DIGILAB FTS 3000 MX type Fourier transform infrared spectrophotometer at $20^{\circ} \mathrm{C}$ with a resolution of $4 \mathrm{~cm}^{-1}$. DTGS type detector was used for all measurements. Background spectrum was obtained using silver coated glass surface. Fifty scans were accumulated for the background and LB films.

AFM measurements were performed in contact and tapping modes at room temperature and in the air using Nanoscope IV from Digital Instrument. Tapping mode was applied to observe topography of silver coated and $\mathrm{ZnSt}_{2} \mathrm{LB}$ films on silver coated glass surfaces. The channel width of electrical measurement setup for in-plane measurement was measured in contact mode (Fig. 1).

The in-plane DC electrical characteristics of zinc stearate LB films between two silver electrodes were also investigated using a Keithley 230 Programmable voltage source and Keithley 485 Auto ranging Picoammeter with time intervals of $5 \mathrm{~s}$ at $20^{\circ} \mathrm{C}$ and $40 \%$ relative humidity as shown in Fig. 2 .

An electrode array has been used to increase DC current in the $I V$ measurement. The $I-V$ characteristics and conductivity data of 13 layers of $\mathrm{ZnSt}_{2} \mathrm{LB}$ film are obtained from the points across one to six using two terminal electrical configuration as shown in Fig. 2, in air and in the range of relative humidity from 20 to $60 \%$ using ACS environmental chamber (Angelantoni Industries) at $25^{\circ} \mathrm{C}$.

\subsection{Water vapor adsorption isotherm of $\mathrm{ZnSt}_{2}$ powder}

One gram of $\mathrm{ZnSt}_{2}$ powder in bulk form was used to obtain water vapor adsorption and desorption isotherms in the same range of relative humidity. The change in mass was measured by means of computer controlled Sartorius GP 603S balance at $25^{\circ} \mathrm{C}$.

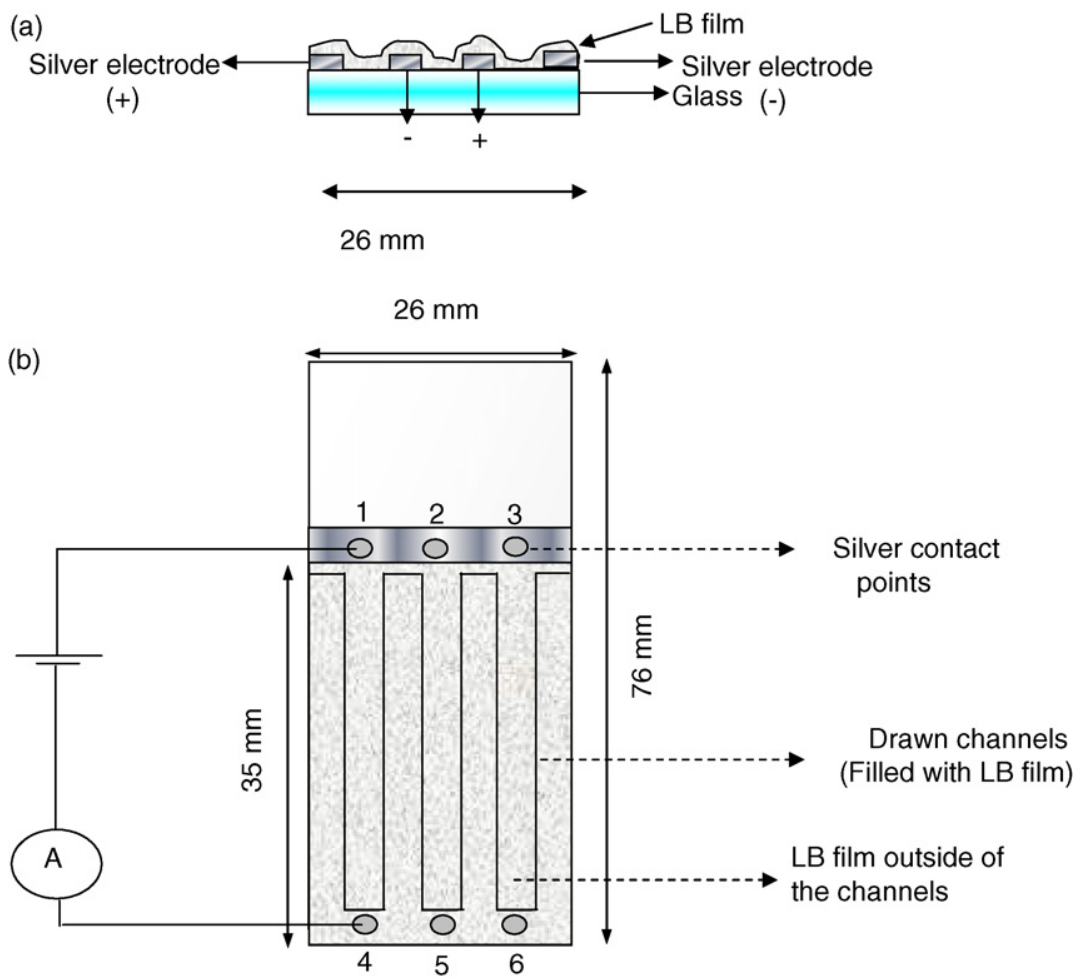

Fig. 2. In-plane arrangement: (a) side and (b) top view representative pictures of $I-V$ measurement set-up. 


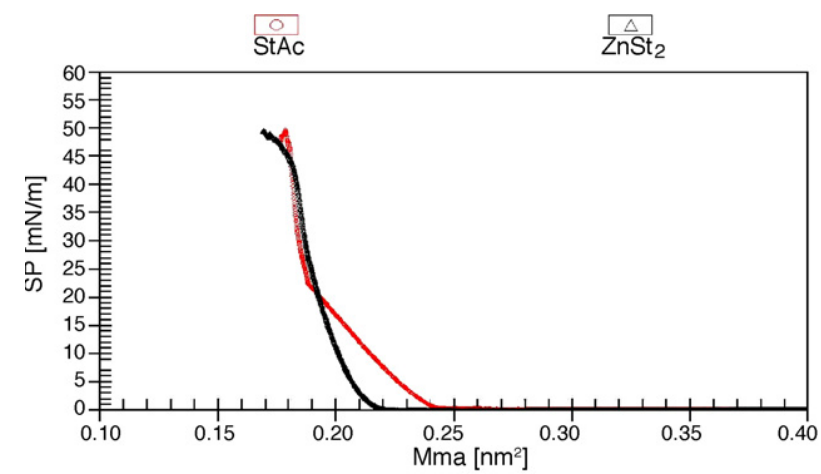

Fig. 3. Monolayer behavior of $\mathrm{StAc}$ and $\mathrm{ZnSt}_{2}$ Langmuir monolayer isotherms taken at $20^{\circ} \mathrm{C}$. pH media (StAc, 5.6; $\mathrm{ZnSt}_{2}, 6.6$ ).

\section{Results and discussion}

\subsection{Langmuir-Blodgett film preparation}

The properties of a stearic acid LB monolayer depend substantially on the ionic content of water subphase. Initial presence of metal cations in the aqueous subphase causes definite changes in the behavior of the monolayer that depend on the nature of the cation, cationic charge, and $\mathrm{pH}$ value of subphase [11,12].

Fig. 3 shows the characteristic compression isotherms of StAc monolayer on pure water and $\mathrm{ZnSt}_{2}$ monolayers prepared on $1 \times 10^{-3} \mathrm{M}$ zinc chloride containing aqueous subphase at $20^{\circ} \mathrm{C}$. In the stearic acid monolayer, the liquid condensed $\mathrm{L}_{2}$ phase and the super-liquid LS phase (solid phase) have been observed while there was only an LS phase in zinc stearate monolayers. Liquid/solid transition is $23 \mathrm{mN} / \mathrm{m}$ for StAc. The molecular area is $1.9 \times 10^{-3}$ and $2.1 \times 10^{-3} \mathrm{~nm}^{2}$ for StAc and $\mathrm{ZnSt}_{2}$, respectively.

The isotherms of all the other stearates exhibit similar behavior [13], like the $\mathrm{ZnSt}_{2}$ curve given in Fig. 3. They are characterized by a very steep slope after a transition plateau which corresponds to the coexistence of "islets" of condensed matter with a very dilute homogeneous phase at very low surface pressures near zero. Limiting surface area is a bit smaller than expected. This may be related to dissolution of monolayer material or slight solvent evaporation during stock of the spreading solution.

Two main types of isotherms shape terminated by a "spike" or a "plateau" in the region of the maximum surface pressure attained was recorded as it is seen in Fig. 3. The "spike" at $\pi_{\mathrm{C}}$ (collapse pressure) can be interpreted as being due to the growth of "organized" trilayers (stabilized by head group hydrogen bonding). The "plateau" at $\pi_{\mathrm{C}}$ might be associated with the irregular fracture of the ionized monolayers [14].

For the same low compression rate like here $(3 \mathrm{~mm} / \mathrm{min})$, the plateau at $\pi_{\mathrm{C}}$ reflects the greater resistance of the monolayer toward transformation into a 3D phase. The limit of the monolayer stability is characterized by the magnitude of $\pi_{\mathrm{C}}$. StAc and $\mathrm{ZnSt}_{2}$ layers collapse at approximately around $50 \mathrm{mN} / \mathrm{m}$ which is quite high value showing stable monolayer behavior.

Addition of $\mathrm{Zn}^{2+}$ cations caused disappearance of the liquid condensed $\mathrm{L}_{2}$ phase. That confirms the well-known phe- nomenon that divalent cations exert a strong condensing effect, yielding solid type monolayers. In these conditions, $\mathrm{Zn}^{2+}$ cations stabilize the floating monolayer by diminishing the repulsion forces between the head groups of stearic acid molecules.

\subsection{Structural characterization}

\subsubsection{Characterization of LB films by X-ray diffractometry}

Grazing incidence X-ray diffraction was used to study the possible packing arrangements in $\mathrm{ZnSt}_{2}$ and StAc LB films. Fig. 4 shows the XRD patterns of 13 layers of StAc and $\mathrm{ZnSt}_{2}$ LB films covered onto bare glass slides.

Thirteen layers of StAc LB film pattern exhibited only very weak and broad diffraction peaks possibly due to the existence of disordered states provoked by possible imperfect film transfer. No sharp diffraction peaks have been observed, since they are not well ordered crystalline. The layer spacing can be determined according to the Bragg's formula. The long-range order of StAc films could not be determined due to limitations of the X-ray diffraction instrument which could not record peaks below $2 \theta$ value of $2^{\circ}$. The distance between successive planes should have been larger than $4.42 \mathrm{~nm}$ corresponding to $2 \theta$ value of $2^{\circ}$.

On the other hand, a peak at $2 \theta=2.08^{\circ}$ corresponding to $4.27 \mathrm{~nm}$ have been identified for zinc stearate. This bilayer dis-
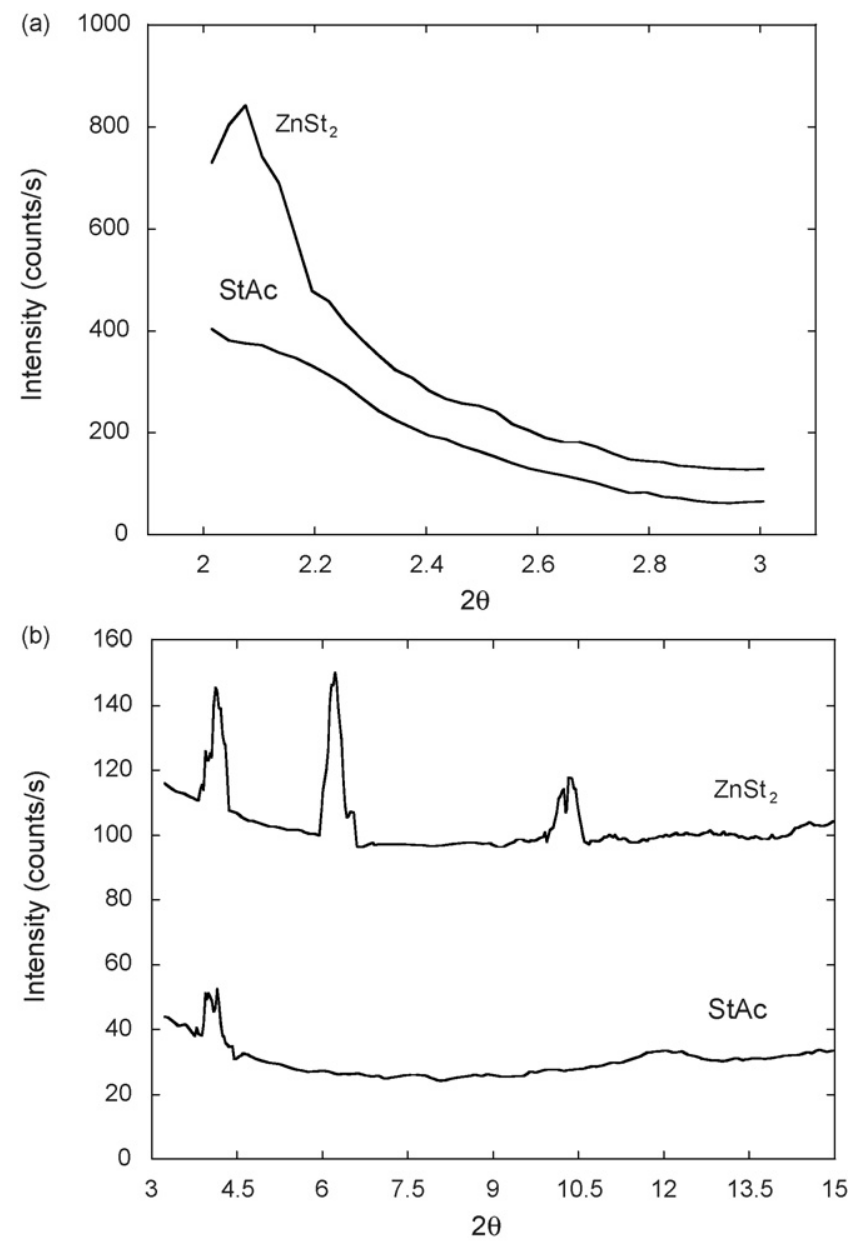

Fig. 4. XRD patterns of StAc and $\mathrm{ZnSt}_{2} \mathrm{LB}$ films on glass (a) at interval $2 \theta=2-3$, (b) at interval $2 \theta=3-15$. 
tance corresponds to a chain axis tilt angle of $31^{\circ}$ assuming the height of the zinc stearate molecule to be $2.5 \mathrm{~nm}$ similar to cadmium stearate reported in Constantino et al.'s work [15]. The same tilt angle was observed for zinc arachidate LB films by Dhanabalan et al. [16] and Kumar et al. [8]. The arrangement under the orthorhombic (R) subcell with chain tilt angle of $31^{\circ}$ may be identified as R(1 11 ) packing. Second, third, fourth and fifth order diffraction peaks at $2 \theta$ values of $4.1 .6 .2^{\circ}, 8.2^{\circ}$ and $10.3^{\circ}$ of bilayer distance have been identified and calculated from Bragg's law $[15,16]$. In Fig. 4 , diffraction peaks at $2 \theta$ values $4.25^{\circ}, 6.2^{\circ}, 10.4^{\circ}$ are observed. These peaks have shoulders at $4.00^{\circ}, 6.3^{\circ}$ and $10.2^{\circ}$ indicating the orientation angle was not strictly $30^{\circ}$, but have a distribution. This distribution broadened the diffraction peaks. Therefore, finding crystal size from the breadth of the diffraction peaks was not possible. The film thickness for this 13 layer film was calculated as $28 \mathrm{~nm}$ from the bilayer distance of $4.27 \mathrm{~nm}$.

\subsubsection{Characterization of LB films by FTIR spectroscopy}

FTIR measurements were carried out to correlate the differences in composition and structure between the LB films deposited from different subphases. IR spectra of 13-layer LB films of stearic acid and zinc stearate on silver coated glass obtained by the $80^{\circ}$ specular reflectance device were recorded between 4000 and $800 \mathrm{~cm}^{-1}$ and given in Fig. 5. The spectra obtained by this attachment are called reflection absorption spectra (RAS) and only transition moment components perpendicular to the silver surface are monitored. The water bands near 3460 and $1630 \mathrm{~cm}^{-1}$ due to the $\mathrm{OH}$ stretching and $\mathrm{HOH}$ bending modes of lattice water are not observed in the spectra since these substrates were dried with $\mathrm{P}_{2} \mathrm{O}_{5}$ for long periods prior to characterization.

3.2.2.1. Stearic acid $(S t A c)$. The weak intensity of antisymmetric and symmetric stretching vibrations $\left(v_{\mathrm{a}} \mathrm{CH}_{2}\right.$ and $\left.v_{\mathrm{s}} \mathrm{CH}_{2}\right)$ at 2922 and $2850 \mathrm{~cm}^{-1}$, which are comparable with those of the antisymmetric $\left(2962 \mathrm{~cm}^{-1}\right)$ and symmetric $\left(2875 \mathrm{~cm}^{-1}\right)$ methyl stretching bands $\left(v_{\mathrm{a}} \mathrm{CH}_{3}\right.$ and $\left.v_{\mathrm{s}} \mathrm{CH}_{3}\right)$ were seen, respectively.

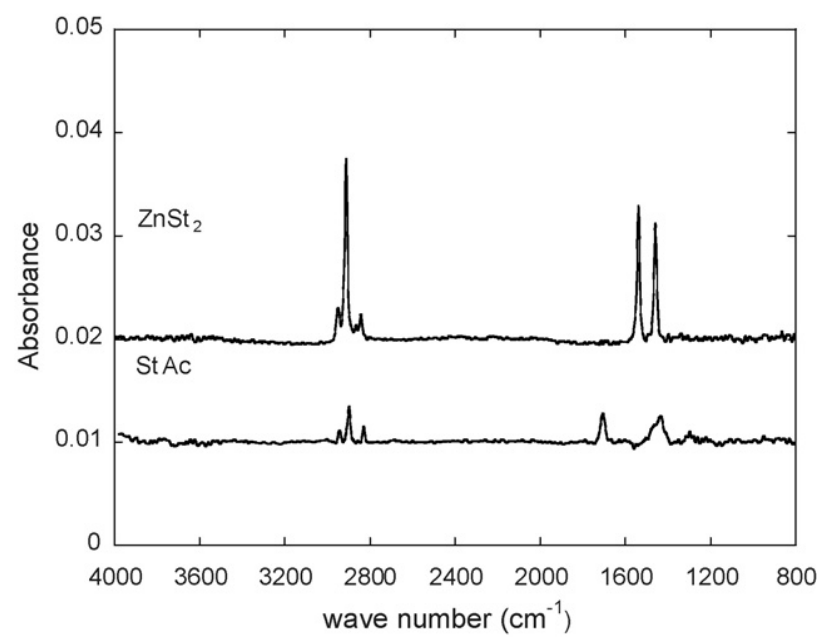

Fig. 5. IR spectra of StAc and $\mathrm{ZnSt}_{2} \mathrm{LB}$ films on silver glass taken with $80^{\circ}$ specular reflectance attachment.
This indicates that the $\mathrm{CH}_{2}$ groups in the LB films are arranged almost parallel to the substrate surface, whereas hydrocarbon chains are oriented vertically. The band observed at $1706 \mathrm{~cm}^{-1}$ is assigned to the $\mathrm{C}=\mathrm{O}$ stretching vibration in the unionized carboxylic group. The broadened $\mathrm{CH}_{2}$ scissoring vibration near $1465 \mathrm{~cm}^{-1}$ is indicative of a "liquid-disordered" subcell packing [17].

Furthermore, the band progression have been seen in StAc layers on silver coated glass from 1400 to $1200 \mathrm{~cm}^{-1}$ which is due to the $\mathrm{CH}_{2}$ wagging mode and characteristics of the alltrans conformation of the hydrocarbon chain. The band near $1300 \mathrm{~cm}^{-1}$ is assigned to a coupled mode of the $\mathrm{C}-\mathrm{O}$ stretching and $\mathrm{OH}$ in-plane bending vibrations and it indicates that the trans configuration is preferable with respect to the $\mathrm{C}=\mathrm{O}$ and $\mathrm{C}_{\alpha}-\mathrm{C}_{\beta}$ bonds in LB films [18].

3.2.2.2. Zinc stearate $\left(\mathrm{ZnSt}_{2}\right)$. Parallel arrangement of the $\mathrm{CH}_{2}$ groups and vertical hydrocarbon chains have been observed in the $\mathrm{ZnSt}_{2} \mathrm{LB}$ films because the symmetric methylene stretching band $\left(v_{\mathrm{s}} \mathrm{CH}_{2}\right)$ at $2852 \mathrm{~cm}^{-1}$ are comparable with those of the antisymmetric $\left(2956 \mathrm{~cm}^{-1}\right)$ and symmetric $\left(2872 \mathrm{~cm}^{-1}\right)$ methyl stretching bands $\left(v_{\mathrm{a}} \mathrm{CH}_{3}\right.$ and $\left.v_{\mathrm{s}} \mathrm{CH}_{3}\right)$. Kutscher et al. indicated that wavenumbers of the antisymmetric $\mathrm{CH}_{2}$ vibration are conformation sensitive and can be empirically correlated with the conformational order [19]. Lower wavenumbers are characteristic of highly ordered conformations with preferential all-trans characteristics. While with increasing wavenumbers and width of the band, the number of gauche conformers increases. According to this expression, $\mathrm{ZnSt}_{2} \mathrm{LB}$ films have highly ordered conformations with all-trans characteristics.

It is noted that the relative intensity of $v_{\mathrm{a}} \mathrm{CH}_{2}$ to $v_{\mathrm{s}} \mathrm{CH}_{2}$ is much higher than those for StAc. The transition moment of the antisymmetric methylene stretching band is perpendicular to the trans-zigzag carbon plane. Therefore, it is indicated that the trans-zigzag carbon plane tends to slightly lay flat on (i.e., not edge on) the substrate plane, giving stronger intensity for the antisymmetric methylene stretching band in the RAS mode. The methylene scissoring band appears at $1460 \mathrm{~cm}^{-1}$.

Absorption bands at 1540 and $1398 \mathrm{~cm}^{-1}$ are, respectively, assigned to antisymmetric and symmetric stretching vibrations of the $-\mathrm{COO}^{-}$group because the carboxylic acid group was ionized and metal $\mathrm{Zn}^{2+}$ ions were introduced into the film. The proton exchange between carboxylic acid and metal salt was completely proceeded since the $\mathrm{C}=\mathrm{O}$ stretching band of stearic acid at about $1700 \mathrm{~cm}^{-1}$ do not appear in $\mathrm{ZnSt}_{2}$ layers.

Kutscher et al. reported that the bonding type of anhydrous carboxylates and in acetates in aqueous solution can be classified by the difference $(\Delta)$ between the antisymmetric and symmetric $\mathrm{COO}^{-}$stretching frequencies [19]. Therefore, $\Delta=142 \mathrm{~cm}^{-1}$ value of the present study can be safely assigned to the bridging bidentate structure [20] where two different metal atoms bind covalently to each of the oxygen atoms of the carboxylate group.

\subsubsection{Characterization of LB films by atomic force microscopy (AFM)}

Two-dimensional topographic images of silver coated glass and 13 layers of $\mathrm{ZnSt}_{2} \mathrm{LB}$ film on silver coated glass are given 
(a)

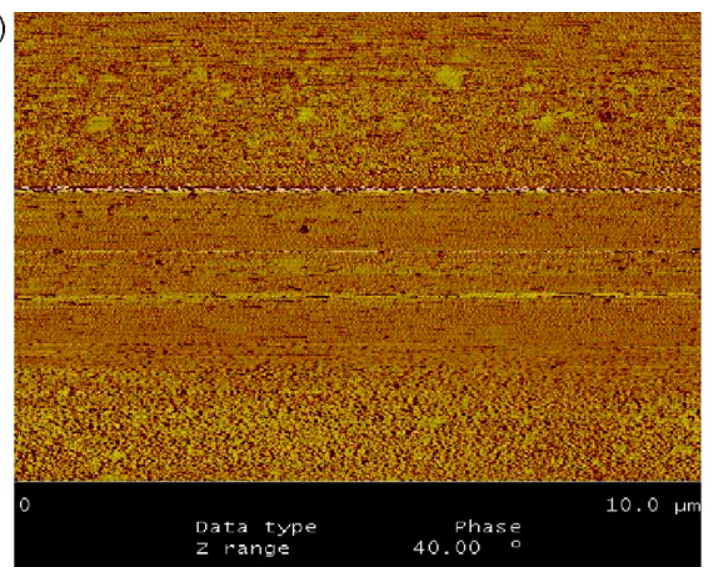

(b)

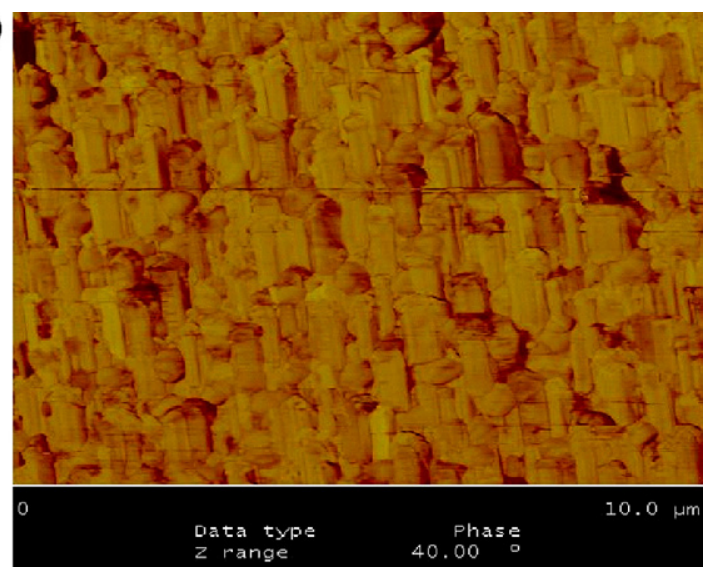

Fig. 6. AFM tapping mode top view phase images $(10 \mu \mathrm{m} \times 10 \mu \mathrm{m})$ : (a) silver coated glass and (b) 13 layer $\mathrm{ZnSt}_{2} \mathrm{LB}_{\mathrm{B}}$ film coated onto silver coated glass.

in Fig. 6. As shown in the image, many holes and grains, especially for LB film coated surface, are presented in the film. The holes correspond to the dark areas of the images, with the lighter "background" being the surface of the films.

Larger patches and grains are especially dominant for $\mathrm{ZnSt}_{2}$ LB film coated surfaces. It is not easy to know whether patches and grains are formed during deposition or upon "drying" of the film in the air. The large crystalline structures might be a kind of island because the zinc stearate may begin to associate to form islands of an ordered phase. The size of these islands is much bigger than the thickness of zinc stearate layers.

\subsection{Electrical characterization}

Typical room temperature $I-V$ characteristics of the 13 layer $\mathrm{ZnSt}_{2}$ monolayer assemblies between silver electrodes at $\mathrm{RH}$ of $45 \%$ are presented in Fig. 7. Since electrical conductivity of glass $\left(10^{-14} \Omega \mathrm{cm}^{-1}\right)$ is very low, its contribution to current flow was expected to be negligible compared to that of the metal soap film. The measured current changes linearly for small voltages. The in-plane conductivity $(\sigma)$ was evaluated from the current and voltage measurements using the equation given in ref. [3]:

$\sigma=\frac{I d}{V l t}$

where $d$ is the distance between the electrodes taken as $80 \times 10^{-6} \mathrm{~m}$ confirmed by the AFM image in Fig. $1, l$ the total

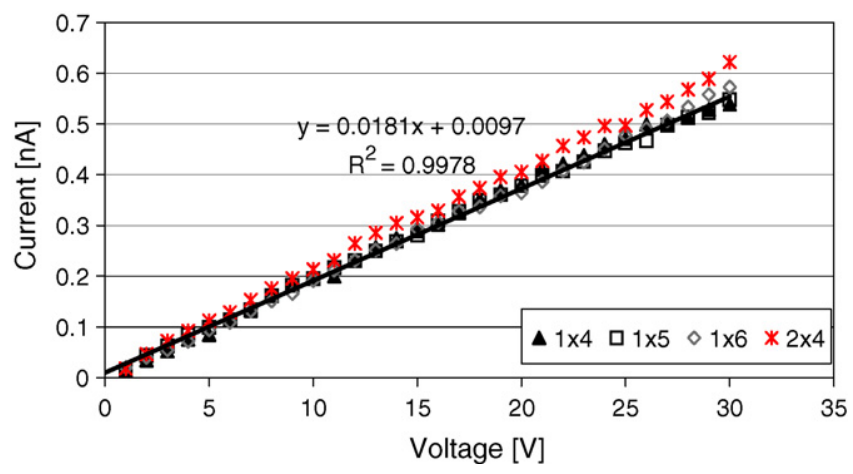

Fig. 7. Current-voltage plots of 13 layer $\mathrm{ZnSt}_{2} \mathrm{LB}$ film at ambient conditions. length of the channel measured as $0.36 \mathrm{~m}$ and $t$ is the thickness estimated as 13 layers of $\mathrm{ZnSt}_{2} \mathrm{LB}$ film $28 \mathrm{~nm}$.

Conductivity versus voltage was calculated for each experimental data point using Eq. (3) and plotted in Fig. 8. Conductivity values were recorded after stabilization of readings.

Water vapor adsorption onto $\mathrm{ZnSt}_{2}$ powder was studied using weight balance prior to humidity behavior experiments for LB films. Since the mass of LB film on the glass slide is very low, direct measurement of moisture adsorption on the film required more sophisticated instrument.

The adsorption-desorption isotherm of water vapor on $\mathrm{ZnSt}_{2}$ powder is shown in Fig. 9. The weight of $\mathrm{ZnSt}_{2}$ increased $0.2 \%$ by the adsorption of water vapor at $60 \%$ of $\mathrm{RH}$ and $25^{\circ} \mathrm{C}$. Hysteresis-like behavior was observed during drying of the $\mathrm{ZnSt}_{2}$ powder showing the uneasy release of water molecules. The adsorption isotherm fitted to Chung-Pfost model is given as follows [21]:

$\ln a_{\mathrm{W}}=A \exp (B V)$

where $A$ and $B$ are the constants for the isotherm model, $a_{\mathrm{w}}$ the water activity (dimensionless) and $V$ is the moisture content. Using Eq. (2), $A$ and $B$ have been obtained as 1.74 and -6.35 , respectively.

$I-V$ and $\sigma-V$ results of our LB film are shown in Figs. 7 and 8. The effect of water hydration in the $\mathrm{ZnSt}_{2}$ multilayer has been

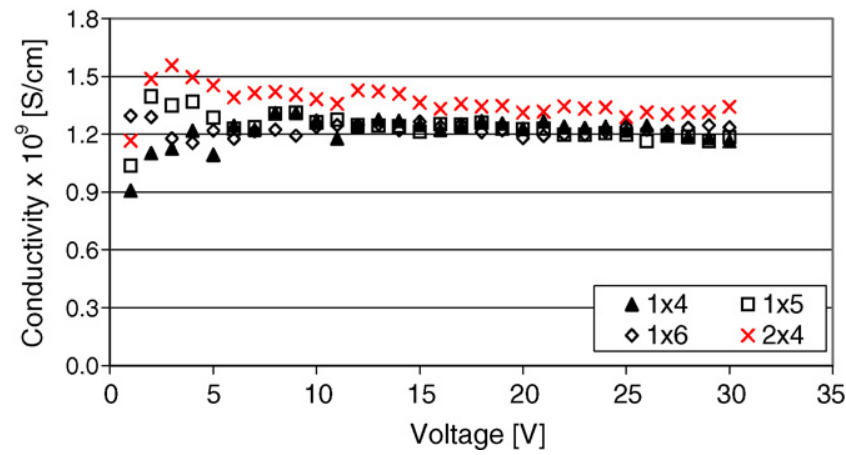

Fig. 8. Conductivity change with voltage properties of $\mathrm{ZnSt}_{2} \mathrm{LB}$ film with 13 layers at ambient conditions. 


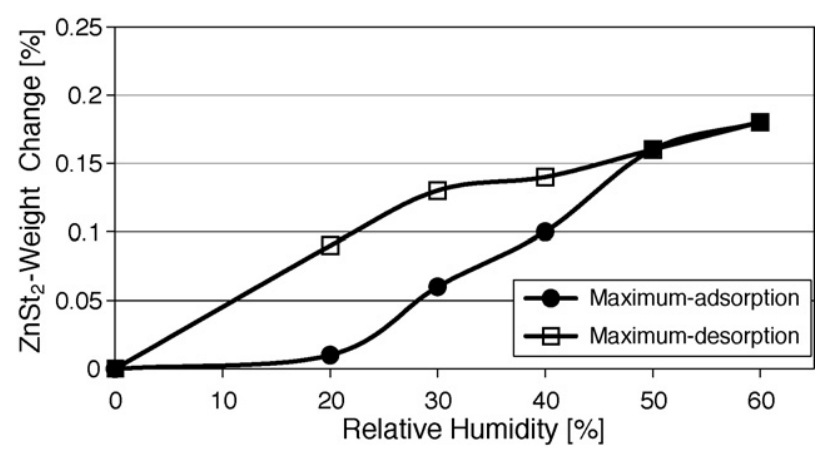

Fig. 9. Adsorption and desorption isotherm of water vapor on $\mathrm{ZnSt}_{2}$ powder at $25^{\circ} \mathrm{C}$.

observed in the electrical conductance [22]. This is unsurprising as the polar nature of water molecules may attract themselves to the head group regions of the multilayer structure. This result is also confirmed with the measurements done in humid atmospheres. Moreover, there is also a contribution of ionic characteristics of $\mathrm{ZnSt}_{2}$ layers to the conductivity of the film.

Conductivity change of $\mathrm{ZnSt}_{2} \mathrm{LB}$ films after exposure to humid atmosphere is given in Fig. 10 for connection points 1 and 4 . The conductivity of $\mathrm{ZnSt}_{2}$ layers was distributed in the range of $10^{-9} \mathrm{~S} / \mathrm{cm}$ in the humid air. The conductivity increased with increasing humidity due to surface adsorption and penetration of $\mathrm{H}_{2} \mathrm{O}$ molecules into organic $\mathrm{ZnSt}_{2}$ layers. In low relative humidity region (20-40\%), the effect of water vapor in the humid atmosphere to conductivity values is relatively small. However, in the high relative humidity region (40-60\%), the strong dependence of current values on relative humidity is clearly seen. In particular, at higher voltages $(>9 \mathrm{~V})$ and higher relative humidity values $(>40 \%)$, sharp increase in conductivity with humidity was observed.

A hysterisis-like behavior was not observed in conductivity measurements of LB films in contrast to water vapor adsorption isothern of $\mathrm{ZnSt}_{2}$ solid powder seen in Fig. 9. Thus, increase in conductivity with moisture should not be attributed to only moisture adsorption onto the LB film. The fast equilibration due to high temperature created from voltage application could be the reason.

$\mathrm{ZnSt}_{2} \mathrm{LB}$ multilayer is anisotropic with different head and tail parts. This property of $\mathrm{ZnSt}_{2}$ gives different sorption capacity

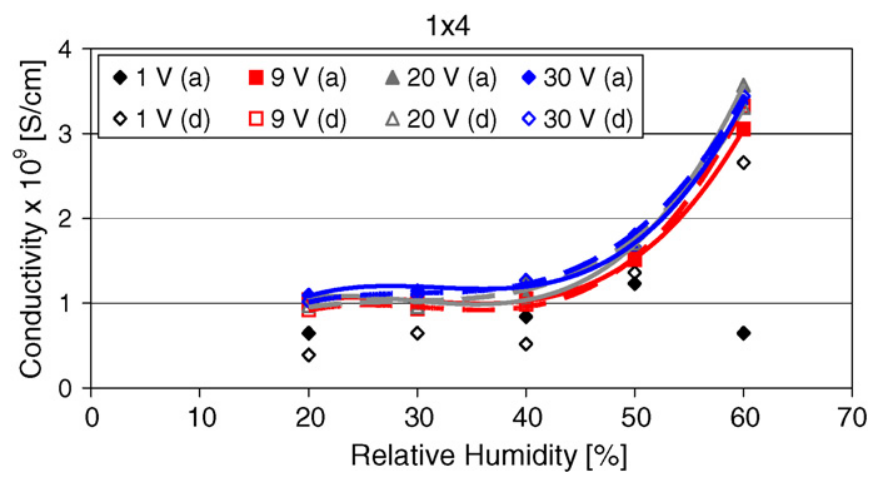

Fig. 10. Effect of relative humidity on measured conductivity at specific applied voltage (a: adsorption; d: desorption) on connection points 1 and 4 . to sorbents as here in water vapor. Although it is assumed that stearic acid molecules well packed into planar structures and individual lamellae are readily and strongly "glued" together with $\mathrm{Zn}^{2+}$ cations, to form well ordered, stable multilayered films, they might harbor nanoscopic regions of disorder or "pockets" with corresponding high and/or selective absorption affinities. Water molecules may "fill the molecular gaps" without introducing much or any expansion of the film or come into contact with polar head groups of the $\mathrm{ZnSt}_{2} \mathrm{LB}$ film.

\section{Conclusions}

Zinc stearate nanofilms by the LB technique were prepared and characterized in this study. The $\mathrm{ZnSt}_{2}$ crystals had the orthorhombic (R) subcell with chain tilt angle of $31^{\circ}$. Bridging bidentate type bonding with carboxylate ion was present in the $\mathrm{ZnSt}_{2} \mathrm{LB}$ film. AFM images showed that $\mathrm{ZnSt}_{2}$ coated surfaces contained grains and defects.

The electrical properties of $\mathrm{ZnSt}_{2} 13$ layer LB films with $28 \mathrm{~nm}$ thickness deposited onto a silver coated glass surface was investigated first time in this work. The conductivity curves taken at varying humid atmosphere emphasized the dependence of electrical characteristics of $\mathrm{ZnSt}_{2} \mathrm{LB}$ films on humidity. No hysteresis in conductivity-voltage measurements was observed for $\mathrm{ZnSt}_{2} \mathrm{LB}$ films during adsorption and desorption of water vapor in the air. Constant electrical conductivity of the $\mathrm{ZnSt}_{2}$ films at low humidities and at low voltage values is an advantageous property which allows us to use them as organic nanofilms with insulating properties.

\section{Acknowledgements}

This study is financially supported with grants for major research projects, DPT2002K120390 and DPT2003K120690 by Turkish State Planning Organization (DPT). We are also indebted Prof. Dr. Mike Petty from Durham University for his valuable technical suggestions and recommendations during the course of this research.

\section{References}

[1] A. Ulman, An Introduction to Ultrathin Organic Films from Langmuir-Blodgett to Self-Assembly, Academic Press, London, 1990.

[2] H. Kusano, S. Kimura, M. Kitagawa, H. Kobayashi, Thin Solid Films 295 (1997) 53.

[3] M.C. Petty, Langmuir-Blodgett Films-an Introduction, Cambridge University Press, Cambridge, 1996.

[4] B. Pignataro, C. Consalvo, G. Compagnini, A. Licciardello, Chem. Phys. Lett. 299 (1999) 430.

[5] L.V.N. Avila, S.M. Saraiva, J.F. Oliveira, Colloids Surf. A 154 (1999) 209.

[6] N. Sigiyama, A. Shimizu, M. Nakamura, Y. Nakagawa, Y. Nagasawa, H. Ishida, Thin Solid Films 331 (1998) 170.

[7] H.G. Hansma, S.A.C. Gould, P.K. Hansma, Langmuir 7 (1991) 1051.

[8] N.P. Kumar, S. Major, S. Vitta, S.S. Talwar, P. Dubcek, H. Amenitech, S. Bernstoff, V. Ganesan, A. Gupta, B.A. Dasannahya, Colloids Surf. 198 (2002) 75

[9] G. Roberts, Langmuir-Blodgett Films, Plenum Press, New York, 1990.

[10] D.K. Kim, Y.S. Choi, J.S. Chang, Y.S. Kwon, Thin Solid Films 327 (1998) 612. 
[11] A. Rajagopal, A. Dhanabalan, S.S. Major, S.K. Kulkarni, Appl. Surf. Sci. 125 (1998) 178.

[12] J. Kmetko, A. Datta, G. Evmenenko, P. Dutta, J. Phys. Chem. B 105 (2001) 10818.

[13] H. Hasmonay, M. Vincent, M. Dupeyrat, Thin Solid Films 68 (1980) 21.

[14] A. Angelova, D. Vollhardt, R. Ionov, J. Phys. Chem. 100 (1996) 10710.

[15] C.J.L. Constantino, A. Dhanabalan, A.A.S. Curvelo, O.N. Oliveira Jr., Thin Solid Films 327-329 (1998) 47.

[16] A. Dhanabalan, N.P. Kumar, S. Major, S.S. Talwar, Thin Solid Films 327-329 (1998) 787.
[17] C. Li, B. Zhao, Y. Lu, Y. Liang, J. Colloid Interface Sci. 235 (2001) 56.

[18] S. Hayashi, J. Umemura, J. Phys. Chem. 63 (1975) 1732.

[19] J.S. Kutscher, A. Gericke, H. Hühnerfuss, Langmuir 12 (1996) 1027.

[20] T. Ishioka, Y. shibata, M. Takahashi, I. Kanesaka, Spectrochim. Acta Part A 54 (1998) 1811.

[21] J.A. Barreiro, S. Fernandez, A.J. Sandoval, Leb-Wiss. U. -Technol. 36 (2003) 37.

[22] K. Ariga, Y. Okahata, Langmuir 10 (1994) 3255. 